\title{
Do Participants Change Their Preferences in the Deliberative Process?
}

\author{
¿Cambian sus preferencias los participantes en la deliberación?
}

\author{
Ernesto Ganuza, Francisco Francés, Regina Lafuente y Fernando Garrido
}

\section{Key words}

Deliberative Forum

- Attitude Measures

- Democracy - Political Efficacy

\section{Palabras clave}

Foro deliberativo

- Medidas de actitud

- Democracia • Eficacia política

\section{Abstract}

This paper analyzes the way participants change their mind in a deliberative forum. Its contribution lies in studying the extent to which these changes persist over time. We start from Mackie's assumption that changes of opinion in a deliberative context cannot be interpreted by considering isolated variables, but must be based on individual attitudinal networks in which preferences are embedded. The results show that certain changes after deliberation are not maintained by some individuals. The paper details the importance of certain variables in the change of opinion in the short and long term, as well as the relationship that exists between different attitudes (information, preferences, beliefs and political efficacy) at three different times before and after deliberation.

\section{Resumen}

El objetivo de este trabajo es analizar el cambio de opinión de los participantes en un foro deliberativo. Su contribución reside en estudiar hasta qué punto esos cambios perduran en el tiempo. Partiremos de la hipótesis de Mackie que sostiene que los cambios de opinión en un contexto deliberativo no pueden ser interpretados considerando variables de forma aislada, sino que deben basarse en la red actitudinal de los individuos de la que emergen sus preferencias. Los resultados nos muestran que algunos cambios no se mantienen tiempo después de la deliberación entre algunos individuos. El trabajo detalla la importancia que adquieren determinadas variables en el cambio de opinión a corto y a largo plazo, así como la interrelación que se da entre diferentes actitudes en tres momentos distintos antes y después de la deliberación.

\section{INTRODUCTION 1}

Deliberative theory stems from a central assumption about understanding politics in deliberative terms: individuals' preferences have an endogenous nature, which means

\footnotetext{
1 This article was made possible by the funding received from the Agencia Andaluza del Agua (AndaIusian Water Agency) and the Proyecto Intramural
}

they are liable to change and are not exclusively determined by material reasons outside of the individual (Besette, 1980). This principle gives rise to the argumentational nature of decisions adopted deliberatively, that is, in a non-coercive environment decisions are

del Ministerio de Ciencia e Innovación (Intramural Project of the Ministry of Science and Innovation) 2010101014

Ernesto Ganuza: Instituto de Estudios Sociales Avanzados (CSIC) I eganuza@iesa.csic.es Francisco Francés: Universidad de Alicante I francisco.frances@ua.es

Regina Lafuente: Instituto de Estudios sociales Avanzados (CSIC) I rlafuente@iesa.csic.es Fernando Garrido: Instituto de Estudios sociales Avanzados (CSIC) I fgarrido@iesa.csic.es 
grounded in arguments precisely because they depend on other individual attitudes (Gutman and Thompson, 2004; Mendelberg, 2002). Deliberative theory's potential comes fundamentally from its capacity to adopt in a regulated way a political process (non-coercive) that rests on an individual mechanism (reflection) which, in turn, calls for argumentation (deliberation) as the main political procedure. This is the crux of empirical comparison within normative theory, and also the general difficulty with deliberation: Is argumentation the crucial feature of a discussion between free and equal individuals? Are the outcomes of deliberation always argued? Do individuals in fact change their minds in the course of a deliberative process?

The starting point of our study is the idea Chambers (2003: 318) launched when she proposed that the central element of deliberation was precisely its capacity to change and even transform the opinions of those taking part. It is assumed that in a non-coercive scenario, participants' preferences change in the light of new information they encounter in the deliberation process and after they exchange reasons for their opinions. The preferences reached after deliberation are thus supposed to be better informed. It is precisely here that the challenge of deliberative theory is to be found (Thompson, 2008: 508), when we try to explain in a non-random way how those opinions change. A better understanding of that process of transformation may enable a better understanding of how deliberation takes place and how it affects the communication process among participants.

In this regard, Landwehr and Holzinger (2010: 379) affirm that deliberative theory lacks a consistent theory about the transformation of preferences that could explain how and why communication affects them. Different compilation studies (Thompson, 2008; delli Carpini et al, 2004) confirm this lack of congruence among the various efforts that have been undertaken with the aim of explai- ning changes in opinion. This diagnosis may describe the usual process of scientific development, with its successes and failures in identifying those elements that best explain the transformation of preferences. But within deliberative theory there is no shortage of proposals for understanding and explaining the transformation of preferences. The theory of the structure of preferences (Dryzeck and List, 2003) is a good example of what we are saying, but so are attempts to explain the transformation of opinion according to $\mathrm{Ba}-$ yes' theorem (Barabas, 2004), advances in psychology (Mackie, 2006) or action theory (Landwehr and Holzinger, 2010).

Among studies of the effects of deliberation the theory of preference structuration offers the most consolidated hypothesis and it has enabled us to understand that preference variability diminishes after a deliberative process, thus challenging the classic idea that individuals' preferences are manifested in cyclical majorities. The studies show how deliberation groups the different alternatives for the individual under a common heading, according to which participants agree to express their greater or lesser commitment to alternatives in descending order (Dryzeck and List, 2003). If preferences tend towards a similar order in a process of public debate, this confirms normative theory, which states that deliberation reduces the overall number of relevant dimensions and the number of alternatives considered in each of them. This means that deliberation would facilitate a shared interpretation of the given situation. Nonetheless, the theory of preference structuration still fails to account for the relation between preferences and other attitudes in order to explain reasonably why and how communication affects changes of opinion. Consequently, we still do not fully understand why preference structuration occurs and what factors influence it. That relationship is fundamental, because if preferences have no relation at all with other endogenous attitudes, the distinctive meaning of deliberative 
theory may get lost, since the meaning of a choice would cease to lie in the dimension with respect to which the different options are evaluated (Landwehr, 2005: 46), thus giving false closure to the problem of preference randomness.

The aim of this paper is to contribute to the analysis of opinion change by considering preferences in their mental context. Our starting point is Mackie's assumption (2006). For Mackie, preference is found within an attitudinal network and a change of opinion cannot be observed as an isolated process, but rather on the basis of a relationship among different attitudes. From this standpoint, a change of preference must be understood as a change in the attitudinal network of which that preference forms part. Mackie has proposed that the change of preference cannot be rationally observed immediately, because according to his assumption changes occur in a long-term process. There would always be a rational process of short-term resistance and a logical conversion in the long term (Mackie, 2006: 299). In an ad hoc deliberative context, such as the deliberative survey on which this paper is based, this evaluation is more relative. The institutional design of a DS (deliberative survey) predisposes participants to listen and attend to the views of the others (Barabas, 2004), which is rather at odds with what happens in ordinary life (Mutz, 2006). So an experience such as the deliberative survey provides an opportunity to better understand why opinions change by considering them as being linked to an attitudinal network. Regarding the hypothesis of long-term opinion, we shall empirically confirm whether the changes occurring in a deliberative experiment persist over time once it has been concluded.

This article is divided into four sections. The first section reviews the points of contact between deliberative theory and studies on the transformation of preferences by analysing the effects of discursive interaction among participants. Next, we describe the research carried out and our working hypothesis. After that, we present the methodology used to analyse the individuals' attitudinal networks. In the following section we present the results obtained from our research and, finally, we discuss those results within the framework of deliberative theory.

\section{DO THE PARTICIPANTS' OPINIONS CHANGE IN DELIBERATION?}

Today it seems there is enough empirical material to maintain that the results of analysing the effects of deliberation upon changes of opinion are ambivalent. Deliberative theory has linked this ambivalence to two distinct problems. The first stems from the insistence of empirical studies on analysing deliberation only on the basis of the variation of aggregated data (delli Carpini et al, 2004: 336). The second problem lies in operationalising individuals' preferences and attitudes as isolated variables (Mackie, 2006; Barabas, 2004). Deliberative theory has worked on the first problem extensively for the last ten years, which has yielded a discussion of the differences between the individuals who participate in deliberation (Mutz, 2006) and the internal processes that mediate between deliberation and its results (delli Carpini et al, 2004; Barabas, 2004; or Wojcieszak et al, 2010). The second problem has been tackled on the basis of the hypothesis that participants' opinions during deliberation do not change in isolation, but in relation to already existing attitudes. That is why changes are never equal among the individuals who take part in deliberation and the process of preference transformation is more complex than might generally be imagined.

The central problem of deliberative theory is to demonstrate that preferences after a deliberative process will be more reasoned than they were before it. The most important studies on the transformation of preferences come from the field of political science. In a 
very simplified way, Phillip E. Converse indicated the variability of preferences by demonstrating that, along with beliefs, they did not seem to be ideologically structured (Feldman, 1988). For many years this made it difficult to explain variations in political preferences, reinforcing the idea that they were random. Zaller and Feldman (1992) gave the problem further impetus when they took individuals' responses (random) in the surveys to be central tendencies within a distribution of possible responses. The change of opinion would take place when an individual decided to accept or reject the arguments she encountered (Zaller, 1992). This consolidated the debate around the effects of speeches by the political elite (framing effects) and their persuasive impact on public opinion. The transformation of preferences would come from variations in the discourse of the political elite, the differences with which individuals attend to those messages and individuals' political predispositions, all of which would affect the distribution of public opinion (Barabas, 2004: 689).

The influence of the discourse of the political elite on citizens' opinions cast the formation of preferences as a phenomenon external to the individual dynamic. However, subsequent studies clarified this problem and opened up the study of frames to the attitudes and interactions of citizens. Nelson (et al, 1997) rejected the hypothesis that the message given offered new information that could transform an individual attitude in the event that the individual was convinced by it. For Nelson the framing effect is not reducible to the new information, but rather it operates by activating information already available to individuals and kept in long-term memory. Thus the effect of messages is aimed more at providing the individual with fresh considerations with which to evaluate the existing alternatives and, in this sense, the message activates existing beliefs rather than contributing new information (Nelson et al, 1997: 235). The effect of a message may be negli- gible when it fails to bring out the attitudes that already exist. In psychology this problem has been dealt with as confirmatory bias, which suggests that most individuals do not use the new information to re-examine their beliefs, but interpret that information from the standpoint of their old beliefs (Kosnik, 2008). A few years later Druckman and Nelson (2003) went further in relativising the effects of the political elite's messages, demonstrating experimentally that conversations among participants could diminish the influence of framing. They concluded (Druckman and Nelson, 2003: 742) that interpersonal discussion among individuals affects the quality of opinion and competes with the message of the political elites.

From the point of view of deliberative theory, advances in the study of framing effects have a special sequel, in that they open up the problem and understand it in terms of preference transformation in accordance with participants' discursive interaction. Preference structuration has provided an explanatory model of preference variability in a deliberative setting. Nevertheless, it does not yet allow us to understand fully why and how preferences change. Barabas's work (2004) is an enormous advance in this respect. On the basis of the literature of framing effects, it understands opinion changes in line with Bayes' theorem which, very briefly, suggests that each individual starts off with what he knows, but brings it up to date with the information he receives. The results of Barabas's study demonstrated that not all individuals start from the same place in a deliberative process, which affects the fact of opinion change itself. Those who have stronger viewpoints change their minds less. In contrast to preference structuration, Barabas offers a specific model of empirical comparison that enables us to explain changes of opinion in a deliberative process.

Together with Barabas, Gerry Mackie (2006) has set out a new way of understanding the problem of opinion transformation. 
Based on studies in social and experimental psychology, it borrows from action theory (Searle, 2004; Moya, 1990) the idea of an attitudinal network. According to this way of thinking, preference change is a process that occurs within an attitudinal structure, from which the participant's final choice (beliefs, preferences, information or civic-political attitudes) arise. Mackie's proposal is interesting in that it offers a broader explanatory model that does not depend solely on the relationship between the information a participant possesses (plus new information) and preferences.

Mackie (2006) questions the results of empirical studies that claim participants in a deliberation do not change their minds, since attitudes and beliefs are not isolated variables but related in a network system (Searle, 2004: 121). As one belief depends on other beliefs and other attitudes, the effects of persuasion on individual opinions cannot be seen directly, but appear as indirect and delayed effects given that they must be consistent with a network of attitudes (Mackie, 2006: 288). Owing to this network, the attitudinal change is not immediate, as the individual opposes a rational process of resistance in the short term (Mackie, 2006: 299). Mackie, drawing upon the tradition of psychological studies developed in the study of framing effects and adopted subsequently by Barabas, suggests making a distinction between strong and weak beliefs, according to whether they are based on more or less direct perceptions. The more a belief rests upon direct perceptions, the stronger it is and the harder to change. Tormala and Petty (2002) confirm this assumption when they point out that attitudes held with a high degree of certainty are more resistant to change than those held with doubts. Accepting the information to which one is exposed is negatively correlated with prior knowledge of the subject, and although those who have more knowledge show a greater readiness to learn, they are also those who put up more resistan- ce to changing their minds (Druckman and Nelson, 2003).

In this paper we shall take as our starting point Mackie's hypothesis (2006), according to which the importance of deliberation does not depend so much on changes in particular attitudes or beliefs as on the possibility that it transforms the attitudinal networks on which an individual's knowledge, attitudes and beliefs rest. The deliberative setting exposes participants to new information, views different to their own and different alternatives on a given subject. This is why it can influence both the acquisition of knowledge and a change in beliefs and attitudes. Deliberation's potential consists in changing opinions so that they become more open to the opinions of others. In this theoretical framework, where the effect of deliberation lies in an attitudinal network, we shall analyse to what extent individuals who participate in a deliberative survey acquire knowledge and change their positions in the light of influential relationships in an individual's attitudinal network, prior to deliberation, at its conclusion and six months afterwards.

\section{THE DELIBERATIVE SURVEY AND THE ATTITUDINAL NETWORK}

The aim of the deliberative survey conducted in 2008/2009 by the IESA (Institute of Advanced Social Studies of Andalusia), in collaboration with the Andalusian Water Agency (Agencia Andaluza del Agua), was to analyse the debate on the management of water resources taking place among citizens residing in the Andalusia region. Given that this region is liable to the rainfall irregularities and seasonal distribution typical of the Mediterranean climate, issues concerning availability and supply of water resources are recurrent subjects of public debate, especially during periods of drought. In general, citizens express opinions and hold particular beliefs and attitudes regarding the subject of water that 
have a direct impact on models of public administration, that is, on the different approaches adopted when it comes to regulating the use and consumption of water resources. While this is not the chief subject of this study, it is worth pointing out that before deliberation $26 \%$ of the interviewees knew the main consumer of water in the region (agriculture), whereas after deliberation that percentage increased to $88 \%$ (table 1). We may assume that the implications of these changes are worth noting when considering the different possibilities of public management of water resources.

The deliberative survey on water was based on the model of James S. Fishkin (1997). The first interview ( $\left.\mathrm{t}^{1}\right)$ was carried out in the first fortnight of October 2008 with a representative sample of the Andalusian population made up of 1,200 people. After that, a Deliberative Forum (DF) was held in the city of Córdoba on $21^{\text {st }}, 22^{\text {nd }}$ and $23^{\text {rd }}$ of November. For the deliberative forum a sub-sample of 120 people was selected from among the 1,200 originally interviewed, in conformity with criteria of representativity by sex, age and level of education. The organising body of the deliberative survey sent an information dossier about water problems in Andalusia to the interviewees who made up this sub-sample.

Finally, 113 participants (out of the 120 selected) attended the forum. There they were able to compare their opinions with those of experts (scientists and representatives of interest groups) who had also been invited and whose speeches embraced the plurality of conflicting positions on the issue of water management. The deliberative dynamic was based on plenary sessions in which participants could ask questions or offer reflections to the experts; they also attended meetings in small groups of eight to ten people where the debate was moderated by a facilitator (Cuesta et al, 2008). At the end of the deliberative forum, the participants self-completed the same questionnaire $\left(\mathrm{t}^{2}\right)$ they had answered in their homes one month before $\left(t{ }^{1}\right)$.
In line with recent deliberative surveys in Finland (Grönlund et al, 2010) and Denmark (Andersen and Hansen, 2007), participants in the deliberative forum were also interviewed some time after it was held, which enables us to make a long-term analysis. In the first fortnight of May 2009, six months after the deliberative forum was held, all the participants were contacted by telephone so that they could answer the questionnaire again. On this occasion 100 individuals collaborated $\left(t^{3}\right)$. The results presented in this paper are limited to the answers of the 100 participants from whom information was obtained in the three phases of the deliberative survey.

The chief aim we set ourselves in analysing the results obtained in $t^{1}, t^{2}$ and $t^{3}$ was to understand the individuals' attitudinal network and to what extent deliberation influences that network. At an aggregate level, we know deliberation has a different effect on individuals (Barabas, 2004; Wojcieszak et. al., 2010), but our question focuses on understanding what is going on in their attitudinal network. Is it true that the acquisition of knowledge influences preferences? What is the relation between knowledge and beliefs or between beliefs and preferences? Is the apparent inconsistency of preferences related to knowledge and beliefs?

In order to confirm whether or not individuals' attitudinal networks do in fact change, we shall analyse the dependence relations among four attitudinal dimensions that usually play a decisive role in the literature on deliberation: knowledge, preferences, beliefs and internal political efficacy. Attitude is a complex term that is usually understood in psychology as the general evaluation a person makes regarding other people (including oneself), things or affairs (Petty et al, 1997). Thus, a person's attitude refers to how favourably or positively she sees an object that is susceptible to judgement. Evaluation may vary depending on whether it stems from emotions, beliefs or experiences, but it is nonetheless widely accepted, regardless of in- 
dividual differences, that everyone evaluates their surroundings at some time (Petty et al, 1997).

The attitudinal network hypothesis means that knowledge, preferences, beliefs, desires and emotions form part of a mental network or structure and therefore the aim is to confirm whether an individual's attitudinal network changes after deliberation and, if so, how. Action theory speaks of mental states to describe any phenomenon that occurs from a subjective viewpoint. Any mental state involves an entire system of mental states (Moya, 1990: 62). So we are not attempting here to find out whether participants learn more or less (Barabas, 2004; Fishkin, 2003), but rather in what way attitudes relate to each other before, after and a long time after deliberation takes place. We chose the four attitudinal dimensions for analysis because, firstly, it is easy to find discussions of them in most empirical studies of the effects of deliberation. Secondly, there is a normative assumption. If we were to reduce deliberation to a relationship between information and preferences, we would precisely be forgetting about the influence and relationship of preferences and beliefs, and whether the latter are strong or weak, which would mean returning to the paradigm of revealed preferences (Landwehr, 2005).

The relation between preferences, knowledge and beliefs is not wholly conclusive. Moreover, if the variations that register the selected variables are shown at aggregate level, it may be observed that the changes fade over time (table 1). Immediately after deliberation the changes we are concerned with are very marked, but six months later they become relativised. There is a common thesis in psychology, known as confirmatory bias (Kosnik, 2008), which we have already seen in the context of how political science has analysed it in the study of the effects of political messages (framing effects). Accepting this thesis has crucial consequences for deliberation because, ultimately, it would su- pport the idea that individuals absorb new information only in order to re-think existing alternatives, but not to modify their beliefs. We have seen in the previous section how Druckman and Nelson (2003) demonstrated that discursive interaction among participants could accept or reject new information and that participants could adopt new stances on the basis of their communicative exchanges. Following Mackie's hypothesis (2006), we shall compare the relation between information, beliefs and preferences in order to examine whether it is true that in the long term, as Mackie says (2006), a change occurs in the attitudinal network. In our case, we shall confirm whether beliefs do not vary with new information and whether the latter modifies preferences. We shall also find out whether changes that occur during deliberation are maintained or transform again.

Finally, we intend to compare the effects of deliberation on internal political efficacy. This is a very common attitudinal variable in deliberative studies. It may be understood as the feeling a participant has about her own competence to be involved in politics or as a subjective measure of individual evaluation of political competence itself (Mattei and Niemi, 2005). Our interest in addressing the subject of internal political efficacy stems from its positive influence on political participation, this being one of the pillars of deliberative theory. However, according to the literature, the effects of deliberation on internal political efficacy are not very clear. Mutz (2006) thinks that exposure to different views, as happens in a deliberative environment, may diminish the sense of internal efficacy. In the same line, Huckfeldt (et al, 2004) claims that with greater exposure to heterogeneous information, an ambivalent attitude towards specific issues increases and therefore the sense of political efficacy diminishes. On the other hand, Hansen (2004) found that mini-public deliberation increased internal political efficacy, although other researchers in deliberative experiments offer conflicting data (Grönlund 


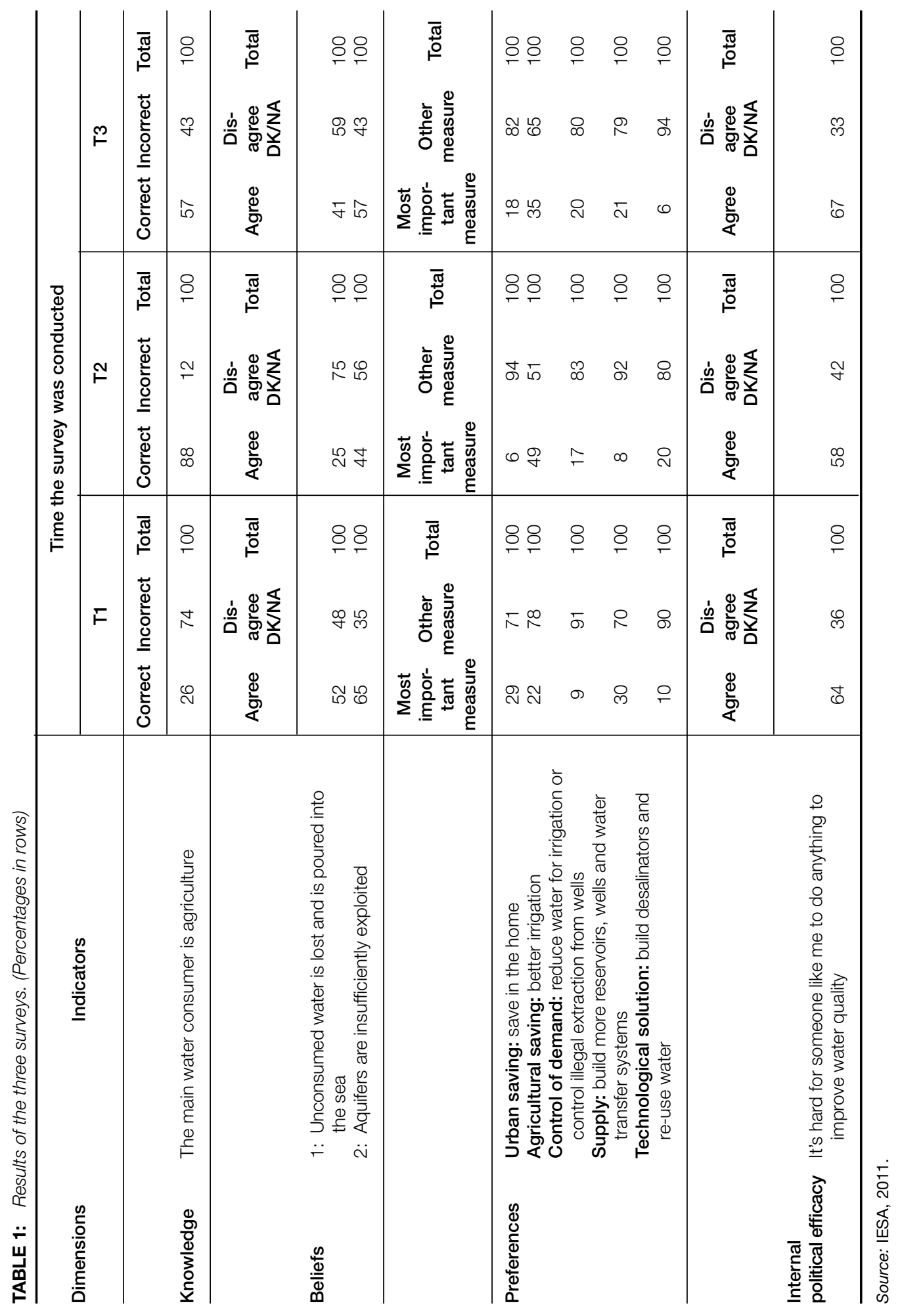


et al, 2010: 98). For Morrel (2005) the influence of deliberation on internal efficacy is very scant. Now, what is the relation of internal political efficacy to other attitudes when we compare them together? Rather than analyse whether or not political efficacy varies with deliberation, our study seeks to confirm whether it changes with new information and whether it is related to modifications of preferences or beliefs in the event that these occur.

\section{Methodology}

The analysis was based on Structural Equation Modeling (SEM), possibly the most suitable multivariate statistical technique for studying and analysing the multiple dependency relations between the variables that form part of a social process. One of the main advantages in using this technique compared to other techniques of multivariate analysis is the possibility of analysing multiple relations among subgroups of variables. The aim is to place the different variables associated with the four dimensions we propose to study (knowledge, beliefs, preferences and internal political efficacy) on the same analytical plane. Each of these acts as a subgroup of variables in a structure linked to the participants' deliberative process. By studying possible variations in the structure, with reference to the three times when the survey was conducted, we should be able to detect the changes that deliberation produces, although not by observation of the dimensions separately, but by integrating in practice the different planes that profile the attitudinal behaviour of those changes.

The goal is to test the structural variations arising in the explanatory chains between variables of the initial structure obtained before deliberation ( $\left(\mathrm{t}^{1}\right)$, by confirming the variance or invariance of that structure at $\mathrm{t}^{2}$ and $\mathrm{t}^{3}$. The procedure was simple. We start with the four dimensions (knowledge, beliefs, preferences and internal political efficacy) and the variables that act as their empirical indicators.

These dimensions acquire a sense within the problem of water resources, so we shall briefly describe the significance of this issue. The two beliefs we use in this study concern the environmental and productive value of water, which were key aspects of the debates that structured the forum and were referred to by the experts in their presentations. Moreover, in Spain, especially from 2004, the political parties also echoed this debate to justify their positions on models of public management of water resources. Thus, if one affirms that 'unconsumed water is poured into the sea, is lost and is not put to any use,' one accepts that all water must be utilised before it reaches the sea. This states a position we have described as productivist, since it overvalues the productive meaning of water. Denying that judgement suggests that one advocates its contrary, which we have called the environmental stance. Likewise, to agree with the proposition 'aquifers are a source of water that is under-exploited,' corresponds to a productivist position, whereas to disagree denotes an environmental position.

Preferences regarding the best public policies for managing water resources also reveal preferences for productivist or environmental positions. For example, if a participant says he is in favour of building more reservoirs, more wells or water transfer systems, he is advocating an increase in infrastructure that will allow a greater amount of water to be stored and extracted from the natural course of a river or an aquifer. He wishes to increase the supply of the resource in order to give it to the productive economy and he therefore maintains a productivist position. On the other hand, if a participant favoured improving land irrigation or saving water in the home, in other words, reducing water consumption (urban or agricultural efficiency), then this would mean he wishes to improve the management of water demand and he 
TABLE 2. Attitudinal indicators

\begin{tabular}{|c|c|}
\hline Dimension & Variables \\
\hline Knowledge & - Correct identification of main water consumer \\
\hline Beliefs & $\begin{array}{l}\text { - (Belief I) Agree/Disagree with the statement "Water that is not consumed is lost and } \\
\text { poured into the sea" } \\
\text { - (Belief II) Agree/Disagree with the statement "Aquifers are insufficiently exploited" }\end{array}$ \\
\hline Preferences & $\begin{array}{l}\text { - Urban saving measures (Agree/Disagree with the proposal "Save water in the home") } \\
\text { - Agricultural saving measures (Agree/Disagree with the proposal "improve irrigation } \\
\text { systems so they consume less") } \\
\text { - Control measures (Agree/Disagree with the proposals "reduce water for irrigation" } \\
\text { or "control illegal extraction of water from wells") } \\
\text { - Supply measures (Agree/Disagree with the proposals "build wells to extract more } \\
\text { water", "build more reservoirs" or "Transfer water from other regions" } \\
\text { - Technological measures (Agree/Disagree with the proposals "exploit sea water" or } \\
\text { "re-use water") }\end{array}$ \\
\hline
\end{tabular}

Internal political efficacy • Agree/Disagree with the statement "It's hard for someone like me to do anything to improve water quality"

would therefore espouse an environmental position.

From the arrangement of the variables that make up these four dimensions, we have devised an explanatory model for $\mathrm{t}^{1}$, based on the working hypothesis, in an attempt to identify the underlying structure of the data, and subsequently adjust the model. Thus, the first model sets out the explanatory relations that are empirically significant among the variables we bring into play. For models $\mathrm{t}^{2}$ and $t^{3}$ the aim was to confirm the initial structure's variance or invariance and possible changes in the coefficient relations among the variables. We believe that this procedure will reveal how the nature of the explanatory burdens in the different models changes due to the impact of the deliberative process and how the size of the coefficients gains weight in some cases and diminishes in others. The result is the identification and testing of the three models.

Having said that, it should be noted that in order to avoid possible bias in the results, the models' specificity was checked to confirm the variability of the coefficients of the different variables at the three times. Consequently, we have discounted possible sample singularities that might distort the results in the sequence of structures presented in the models.

\section{Evaluation of the empirical adjustment of the models}

The process of evaluating the models is usually carried out according to three sources. In this study we present two of them. The first is the evaluation of the global goodness-of-fit indices. The second is the consideration of the significance of coefficients of relation among the variables that appear in the diagrams of the models. These coefficients, which will become clearer as the narrative thread of the study develops, will help us to graphically evaluate the dependence relations among the variables that form part of the models. It must be remembered that the diagrams express only those coefficients with sufficient empirical significance. We have left out the third evaluation source, structural equations, as it is not directly rele- 
TABLA 3. Coeficientes de bondad de ajuste

\begin{tabular}{lccccc}
\hline Statistics & Variations & $\begin{array}{c}\text { Recommendable } \\
\text { values }\end{array}$ & $\begin{array}{c}\text { Values } \\
\text { model } \mathbf{t}^{\mathbf{1}}\end{array}$ & $\begin{array}{c}\text { Values } \\
\text { model t }\end{array}$ & $\begin{array}{c}\text { Values } \\
\text { model } \mathbf{t}^{3}\end{array}$ \\
\hline RMSEA & & $<0,05$ & 0,000 & 0,000 & 0,000 \\
$p$ - Value & $0-1$ & $>0,05$ & 0,76044 & 0,54153 & 0,84207 \\
GFI & $0-1$ & $>0,90$ & 0,98 & 0,95 & 0,97 \\
AGFI & $0-1$ & $>0,90$ & 0,94 & 0,90 & 0,93 \\
NFI & $0-1$ & $>0,80$ & 0,91 & 0,77 & 0,90 \\
NNFI & $0-1$ & $>0,95$ & 1,00 & 0,98 & 1,00 \\
SRMR & & Close to 0 & 0,058 & 0,061 & 0,065 \\
\hline
\end{tabular}

vant to the proposed hypotheses and may hinder the presentation of our study.

The fit indices most often used for validating models are the Chi-square, degrees of freedom, RMSEA (Root Mean Square Error of Approximation) and $p$-Value. The Chi-square is a measurement of global data model fit. In the three models used the size of the chisquare and the degrees of freedom present relatively balanced sizes, which indicate adequate fits. In any case the statistical tests based on chi-square are not very sensitive in the case of small samples and for our analysis, given that we are working with a limited sample (100 cases), we have employed additional indicators to evaluate the model's fit.

Jöreskog and Sörbom (1989), the creators of the Lisrel programme, which is the one we used for the models, recommend using two fit indices: the Goodness-of-Fit index (GFI) and the Adjusted Goodness-of-Fit Index (AGFI). For the evaluation of fit of structural models, Rex Kline (1998) also recommends reading the results of three further statistical tests: the NFI (Normed Fit Index), the NNFI (Non-Normed Fit Index) and the SRMR (Standarized Root Mean Square Residual). In the following table we see the results of all these indices for the three models proposed.

As we may observe, the fit indices have values within the margins assumed as acceptable. The fit tests show very low RMSEA coefficients ( 0.000 in the three models), as well as a much higher probability than $0.05\left(p=0.76\right.$ in $t^{1}, 0.54$ in $t^{2}$ and 0.84 in $\left.t^{3}\right)$, which indicates that the models we propose fit correctly with the data and are capable of capturing the reality being studied.

\section{THE ATTITUDINAL NETWORK AND PREFERENCES IN WATER MANAGEMENT}

The results obtained before participation in the deliberative forum show (figure 1) how participants' knowledge of the distribution of water consumption is significantly related to preferences regarding the management of this resource. Irrespective of whether citizens possess accurate or erroneous information on the subject, there is a strong identification and coherence between who is believed to be the main consumer of water and who should be required to make a greater effort to consume efficiently. Most of those who responded to the survey before deliberation had erroneous knowledge about the main consumer of water, which they believed to be the home. They supported urban efficiency measures. On the other hand, those who knew that the agricultural sector was the chief water consumer in the region favoured saving water in agriculture by improving land irrigation systems.

According to the results of the first survey (see table 1), the beliefs of Andalusian people concerning water highlight its productive na- 
ture. Most participants considered that 'water poured into the sea is wasted' (belief I) and that aquifers are under-exploited (belief II). However, there is no consistency between both beliefs, that is, they are not mutually related and also reflect an attitudinal inconsistency towards the water problem. Those who think that 'water poured into the sea is wasted' and who support measures to increase supply hold a coherent position, but those who think that aquifers are insufficiently exploited and yet do not support measures to increase supply display a certain inconsistency. One might suppose that if an individual's beliefs place her on the side of the productivists with regard to the water problem, she would support models of management aimed at increasing, for example, the infrastructure that enables a greater amount of water to be stored (increasing the supply of the resource). This is partly true. In Model 1 there is a positive relation between belief I and preference for measures to increase supply, but we find a negative relation between these measures and belief II. This result reflects an attitudinal inconsistency, since the same belief about the value of water (productive nature), measured with two different indicators (river water and underground water), correlates in a conflicting way with the same management options. This phenomenon manifests the inconsistency of individual attitudes, with participants capable of maintaining two apparently contradictory things.

Indeed, the attitudinal network of individuals before deliberation seems to relate the type of information they possess (whether accurate or not) to preferences for management measures, but not to beliefs they hold about water, which moreover have no significant relation at all with the information. In their turn, beliefs have no relation to each other and are related inconsistently with management options. Finally, internal political efficacy does not seem to be statistically linked to any of the elements included in the model. Therefore, we understand this dimen- sion to have no influence before deliberation upon the other attitudes analysed.

Like most of the deliberative processes analysed in the literature, participants' attitudes and opinions in the deliberative survey on water changed once the deliberative forum was concluded. Model 2 analyses to what extent the changes were significant and how the different analytical dimensions (knowledge, beliefs, preferences and internal political self-efficacy) are related in this new phase. If deliberation generates more reasoned opinions then significant relations would have to appear among the dimensions, that is, the changes of opinion caused by knowledge acquisition would have to register in individuals' attitudinal networks, modifying some of their components and relations, otherwise the changes would be merely superficial.

As we see in Model 2, after deliberation preferences have acquired an extraordinary independence in the attitudinal network. The public management of water focused the debates of the deliberative forum, creating a space for different interest groups and experts to express their management proposals. Each proposal was debated and evaluated by all participants, who eventually assessed the advantages and drawbacks of all the measures included in the model. At aggregate level (Table 1) the participants shifted responsibility for the water saving effort from homes to agriculture. While in the first survey 29 people considered the effort ought to lie with home consumption as against 22 people who mentioned land irrigation improvement, in the second survey it was the agricultural sector that was required to make the greater effort (49 people) and only 6 people supported domestic saving. Only the measure relating to agricultural water saving is linked to the other dimensions analysed in the attitudinal network, although it is not directly related to knowledge. In fact, in contrast to what is observed in Model 1, this time knowledge is not directly related to preferen- 
FIGURE 1. Model 1

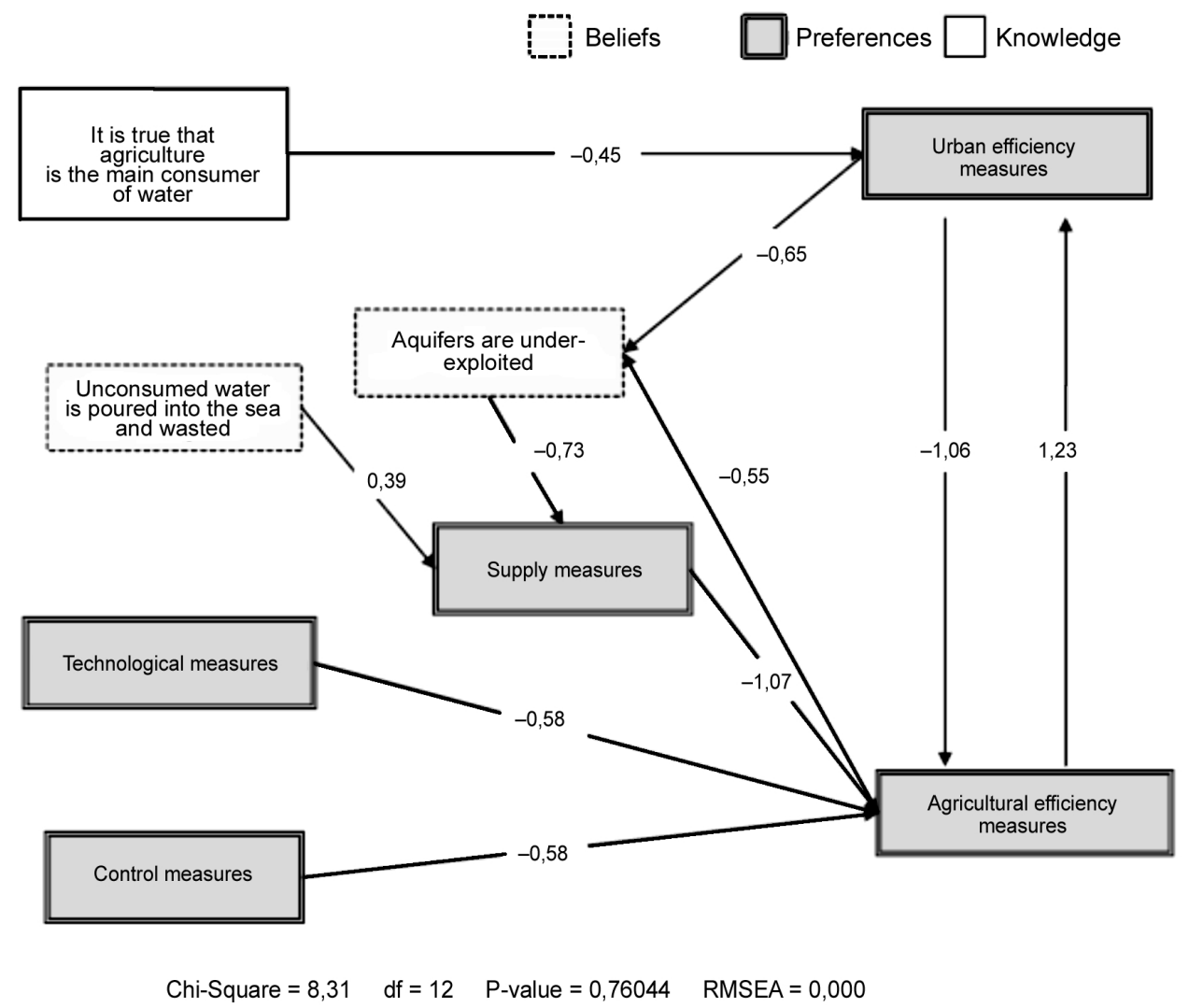

ces; its relation with these is mediated by beliefs.

Once participants acquire correct information about how water is distributed among the productive sectors, knowledge of this subject becomes widespread and $88 \%$ of the interviewees answer the question on this issue correctly. It is logical that if, in the new context, knowledge has become widespread, this should not help to identify participants' choices about the most suitable measures for improving the management of the resource. Preferences are now linked to participants' beliefs about water, beliefs that acquire in this model a central role in the attitudinal network, and which have, in turn, been modified on the basis of acquired knowledge.

Therefore, in this case, knowledge and the deliberative process are used to revise citizens' beliefs about water, which in aggregate terms turn towards more environmental positions (three out of four participants now consider the water flowing into the sea to have some use). Moreover, in Model 2 beliefs have a significant and coherent relation with each other. This whole change reasonably explains the central place of the preference for water saving in the agricultural sector. And this supports the hypothesis of preference structuration and the sidelining of, for exam- 
ple, preferences for increased supply measures or urban savings with regard to Model 1.

Contrary to what other studies have claimed (Morrel, 2005; Grönland et al, 2010), after deliberation internal political efficacy is included in citizens' attitudinal networks in a significant way. Specifically, the indicator that measures internal political efficacy relates positively with belief $I$ : those who share a more environmental position with respect to this belief (they think river water that reaches the sea is not wasted), display a higher level of internal political efficacy. The fact that this goes in the same direction as participants' aggregated opinion in $\mathrm{t}^{2}$, shows the effect preference structuration may have on participants: it not only serves to share an interpretation of the given situation, but also increases their internal political efficacy. It seems clear that environmental positions managed to infect participants with a sense of political efficacy, by signalling that from such positions they were able to contribute to solving the water problem. The interesting thing about the change is that it takes place in relation to beliefs but not to knowledge or preferences. That may help us to clarify the problem of confirmation bias, as in some way we can see that the deliberative context helps participants to re-examine the beliefs they hold, which in turn significantly influences other attitudinal dimensions. So, what happens six months later? After that time lapse one might suppose that any deliberative effect had faded and, therefore, we could find out to what extent deliberation had really influenced the participants' attitudinal network in the long term.

Model 3 is constructed on the basis of the results obtained six months after the deliberative forum was held. Throughout this period the deliberative intensity around the subject of water was absent. According to what we observe in the chart, the attitudinal network depicted in the third model is quite similar to that analysed in the first one, when participants were interviewed for the first time, wi- thout having taken part in the deliberative forum. Just as at that time, not knowing that the main water consumer in Andalusia is agriculture is associated with favouring urban water savings. Likewise, knowledge ceases to be associated with beliefs, which was one of the main effects participation had upon the individuals' attitudinal network in the forum (see Model 2). Moreover, holding productivist positions with respect to beliefs is associated with supporting measures aimed at increasing the supply of the water resource. While these are the chief similarities between Model 3 and Model 1 (beliefs cease to be related to information and preferences are more intensely related to it), which suggest to us that the effects of the deliberative forum on the individuals' attitudinal network were somewhat ephemeral, we also find some evidence of deliberation's footprint in the participants' attitudinal network.

Firstly, the deliberative forum was effective in transmitting information on the subject of water. Of the 88 people who answered correctly in the second survey, 21 already knew this information; while of the 67 who 'learned' it during the forum, 33 maintained the knowledge six months later, although the other half forgot it (34 people). The negative relation between knowledge and management measures focussing on urban water saving indicates that those who keep the knowledge acquired during the forum advocate another type of public water management measures (in line with the positions adopted after deliberation).

Secondly, after the deliberative forum was held, internal political efficacy was maintained in the participants' attitudinal network. In the third model it does not appear associated with beliefs, but rather it is related positively with knowledge. In Model 2 the relation between internal political efficacy and knowledge was indirect. Therefore, the new relation shows that the acquisition of knowledge is not an isolated phenomenon, but rather related with other attitudes. This may be due to 
FIGURE 2. Model 2

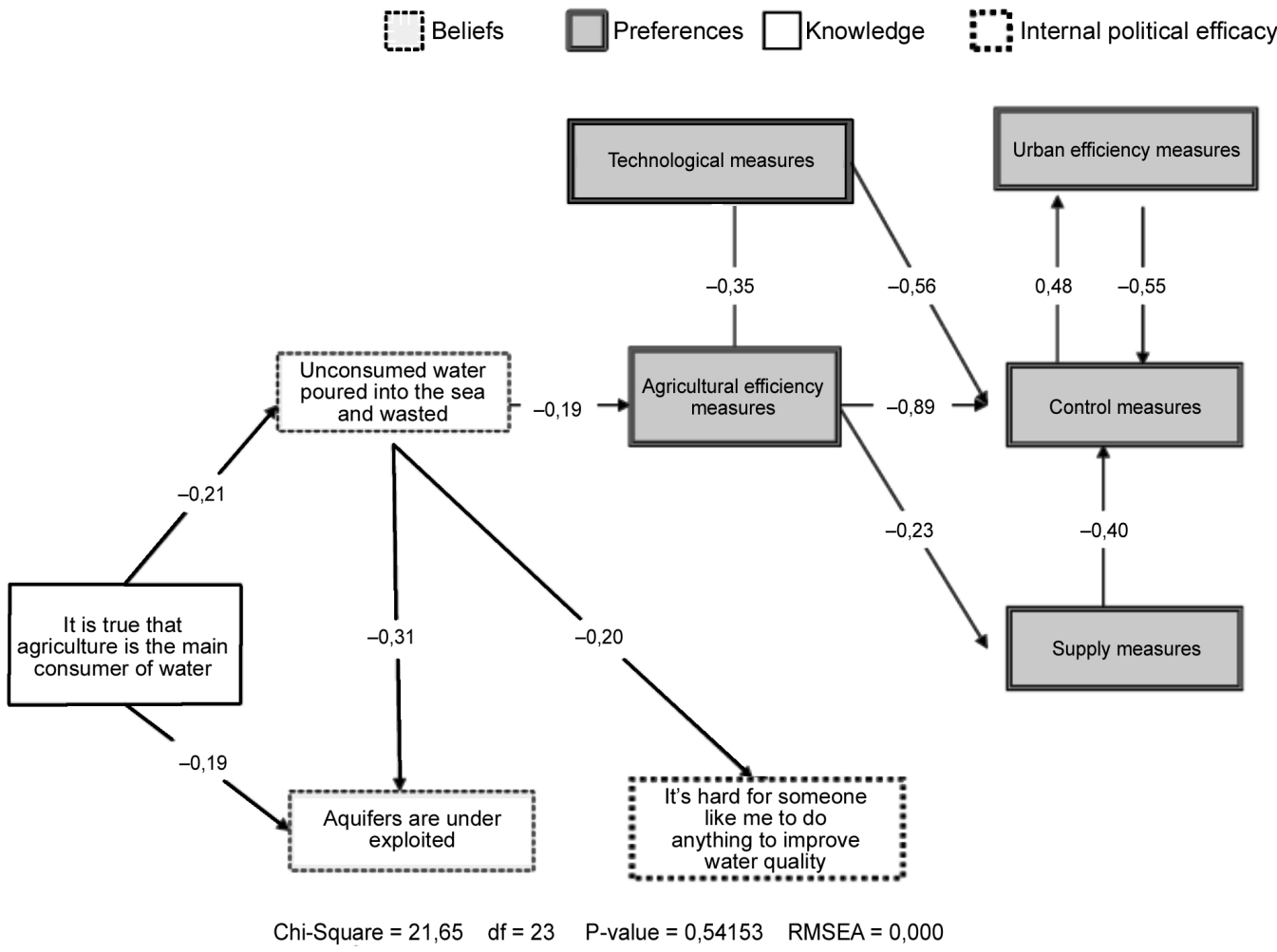

the fact that in Model 3 knowledge distinguishes once again among participants, at least to a greater extent than it did in $\mathrm{t}^{2}$. It should be observed that aggregate levels of internal political efficacy (table 1) did not vary much throughout the three surveys. However, within the attitudinal network, internal political efficacy became significant after deliberation, above all for those who preserved what they had learned. This tells us that the changes that occurred in deliberation have made that variable significant in relation to the other attitudinal dimensions, which was not the case before.

Thirdly, after the deliberative forum was held, citizens' beliefs about water continued to have the internal coherence they acquired (see Model 2). Even though the indicators used in the survey to measure whether AndaIusian people recognise a productive or an environmental value in water correlate positively, their relation with preferences followed somewhat different paths. The aggregated results about beliefs (table 1) show that the population finds it easier to recognise the environmental value of water in rivers than in the underground waters of aquifers. In the third survey, most participants chose more environmental measures based on efficient consumption (in homes or in agriculture), irrespective of whether they thought about aquifers or river volume in productive or environmental terms. As Model 3 shows, beliefs now have no significant relation with this group of measures. However, support for 
FIGURE 3. Modelo 3

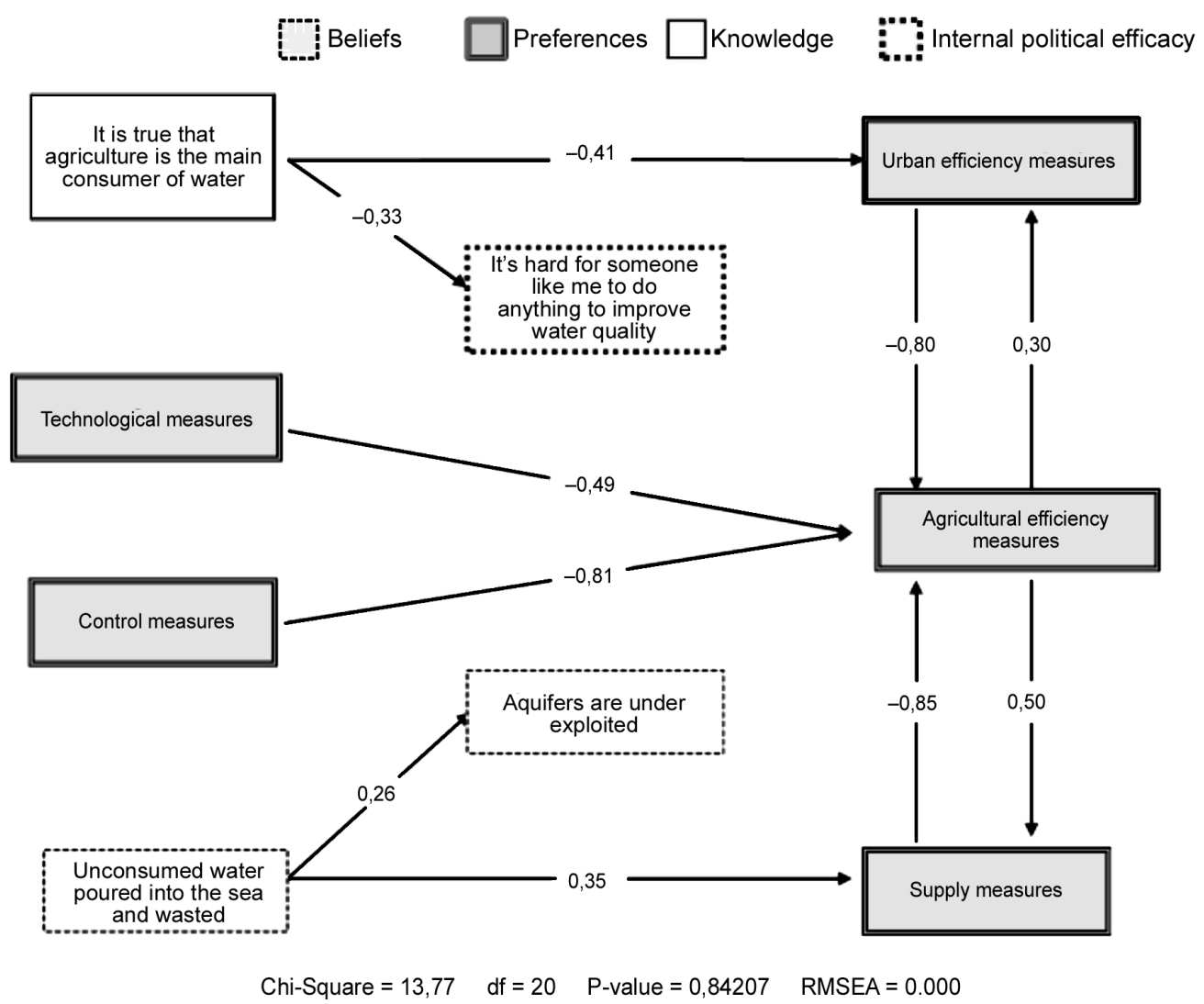

measures based on the building of infrastructure to increase the water supply largely correspond to those who think that water flowing into the sea is wasted and has no use and, indirectly, that aquifers are not sufficiently exploited. We might think that to some extent the turn in participants' opinions after deliberation (towards management preferences that rationalise consumption) lose their consistency with beliefs, contrary to what occurred in Model 2, although those participants who stray from the majority by choosing measures aimed at increasing the water supply continue to be significantly supportive in their beliefs.

\section{Conclusions}

The deliberative forum has an extraordinary power to change its participants' attitudinal network. We are not speaking only of a change of opinion, but of one that is supported by other attitudes. As Barabas shows, the acquired information serves to bring opinions up to date, but following Mackie, everything rests, in turn, on the transformation of other attitudes. Before deliberation, most participants who believed that 'water that reaches the sea is wasted' preferred measures to increase supply in water policies that would allow larger volumes of water to be stored or captured, such as the building of reservoirs or 
wells. Moreover, the majority incorrectly believed that most of the water resources went to domestic consumption, which markedly influenced their preferences for managing the resource with water saving measures in the home. After the debate forum, that connection was transformed. Information about the real distribution of water consumption among the different productive sectors affected both beliefs: that relating to river volumes and that relating to underground water. These in turn influenced participants in preferring water saving measures in agriculture. Furthermore, those who learned that most water goes to land irrigation adopted environmental positions regarding both beliefs - a co-ordination that did not exist before their participation in the forum. If that were not enough, contrary to the results of other studies (Morrel, 2005), we find that internal political efficacy was significantly related to this new attitudinal network, whereas before it did not even appear.

Up to this point we can confirm Barabas's hypothesis and also Mackie's. Deliberation can transform opinions and also change participants' attitudinal network. However, six months later, the attitudinal network partly regresses to its old ways. This indicates that a deliberative context as intense as the one that occurs in a deliberative forum produces substantive changes in the attitudinal network, but this change is diluted over time. If we imagine the deliberative forum as a laboratory, we might say that changes weaken outside it.

How can we explain this? The first thing we should consider is what Barabas emphasised. An ad hoc deliberative scenario is expressly designed so that participants assume an open attitude to the opinions of the others. This has been confirmed by studies comparing a public that attends a deliberative process with another public that does not. In those studies the first public learns and changes its attitudes more intensely (Barabas, 2004; Landwerh and Holtzing, 2010). The conclusion that deliberation has significant effects on participants' attitudes is not less valid as a result of this. Studying a phenomenon under controllable conditions is customary in science. A more pertinent question here, raised openly by Thompson (2008), would be how to transfer the deliberative context to the political dynamics existing today. This question has already stimulated studies in deliberative theory on the institutional conditions that more or less favour the deliberative attitude of participants in different contexts (Landwerh and Holtzing, 2010; Steiner, J and Bächtiger, M, 2005). The question has even boosted the study of deliberation and its conditions in contexts as diverse as the social movements (della Porta, 2005) or the new instruments of participation (Ganuza and Francés, 2012; Talpin, 2011). Mackie (2008) even speaks of the deliberative effects that electoral dynamics have on participants. This is a field in which deliberative theory is certain to develop, because a 'trial' does not wish to remain in the 'laboratory', although the path that leads from micro-publics to the macro-public is still an uncertain course.

Secondly, we cannot discount the idea that while an ad hoc deliberative scenario favours its participants' deliberative predisposition, once outside it participants relativise their positions on the issues raised. Not all participants had the same expectations about the deliberative forum to which they were invited, just as not everyone drew the same conclusions. The data shows us this reality in a relevant way. The fact that internal political efficacy became significant after deliberation and not before is evidence that learning endows participants with a greater sense of their capacity to exert influence. Even though studies on deliberation are not very conclusive with regard to its effects on the internal political efficacy of individuals, the relations discovered between this variable and the other attitudes analysed allow us to confirm that internal efficacy becomes established among those who preserve what 
they have learned. This implies a very interesting contribution from the point of view of normative theory.

We might expect that the change of opinion and beliefs will last only if that change gives individuals a plausible outlook where they may act according to their own positions and life networks. This would support the thesis that individuals are more willing to recognise their own interest, and to act in consequence, when they associate a political debate with the personal costs and benefits that one or another option might bring to their lives (Chong et al, 2001). In our case, the deliberative forum afforded participants the conditions necessary for re-examining their positions on how one ought to manage a public resource such as water, which is present in their daily lives and for which they shoulder a certain economic burden in paying their bills. This re-examination takes place especially when they discover that $80 \%$ of water resources go to land irrigation, together with the fact that in the deliberation all the experts maintained that the urban water supply is always guaranteed in a region whose citizens have periodically been subject to complaints by the authorities and urged to manage their domestic water consumption efficiently. Brikman and Peterson (2006) have also proposed that the influence of public debate has a lot to do with the ability to link individuals' political predispositions with their attitudes towards the problem. In the context of the debate on water resources this proposal means that internal political efficacy becomes significant among those participants who learn that the main water consumer is agriculture and begin to believe in the need to preserve the entire water cycle, recognising the importance of the aquifers and the environmental value of river water that reaches the sea. Compared to the participants' points of reference before they attended the deliberation, for many of them this whole process increased their feeling of influence or empowerment with regard to their individual position on the subject of water. In a way, deliberation allowed them to look at the problem from another angle. In part, they modified their attitudes towards water and now feel themselves to be more competent agents to influence the future of water resources in the region.

On the other side of the process we have the participants who learned during deliberation, but did not retain their knowledge six months later. In comparison with the others they have a negligible level of internal political efficacy. From this viewpoint, one might think that these participants have not managed to link the debate with their own interests and have returned to their previous attitudinal background. It is relevant that internal political efficacy and preferences for saving water are linked before and after with knowledge, while participants who advocate productive preferences are mainly those who believe that 'the water that reaches the sea is wasted'. This happens before and after deliberation, but not while the deliberative forum is being held. We might suppose that these participants had a more closed or cohesive attitudinal stance before deliberation and that six months later it reappeared. Barabas (2004) has already demonstrated the importance of participants' pre-deliberative situation when analysing the effects of the deliberative process. Six months later, these participants fall back upon their old beliefs. Therefore, what the hypothesis about confirmatory bias suggests - that the new information does not serve to transform beliefs - is not so certain: rather the new information is disregarded in the long term so as to maintain coherence with the old beliefs. But, why did they change their opinions during deliberation?

When we examine the data in our study, information was the key to this change. It must be taken into account that the type of information we are considering is simple, but at the same time qualitatively changes understanding of the world of water. Agriculture 
consumes almost $80 \%$ of available resources and homes use only $15 \%$. If a participant prior to attending the forum believed that most water went to domestic consumption, her perception of water as a problem would be different. The change that occurred after deliberation demonstrates this. The new information had a significant influence on participants' beliefs, even on those who held productivist beliefs about the use of water from the aquifers and rivers. Furthermore, preferences took on a more direct relation to beliefs than to information. Similarly, internal political efficacy also became significant for participants who modified their beliefs about water. Deliberation modified the participants' attitudinal network, but did not manage to supplant the old one in the long term.

The fact that some of the participants returned to their initial state confirms the existence of individual differences among those attending a deliberative process. But it is also evidence for the limits of cognitive learning, or else it shows that attitudinal changes are connected with many more factors than those we are considering. Petty (et al, 2003) suggests that it is an error to think that an attitudinal change necessarily implies the complete replacement of some attitudes (new) by others (old), given that the latter persist in memory and may influence an individual's behaviour. If it is indeed true that old attitudes remain, this would contribute an indication of how consistent deliberative changes are. For example, the more solid the old or initial attitudes, the weaker the effect of deliberation in the long term. In our case, that may be demonstrated if we observe that participants whose preferences stemmed from their beliefs (always of a productivist kind) return to them six months later, even after having changed them during the deliberative forum.

Mackie's (2006) hypothesis about the influence of deliberation in the long term can be maintained, although it is untrue that there is no short-term change in the attitudinal net- work, at least if we are considering an intense deliberative context such as a deliberative survey. Perhaps Mackie's hypothesis is true in the everyday open dialogue he imagines, but in a deliberative forum the immediate change is considerable, although maybe for that very reason it is also more fragile. Let us take preferences as an example. Before deliberation, preferences at aggregate level were coherent with the knowledge shared by most participants. Just after the deliberative forum, preferences take on a remarkable independence with respect to knowledge and are influenced by the new beliefs. On the other hand, six months later, they fall into the same pattern as before deliberation. On the one hand we have an attitudinal network that reestablishes itself on its origins and, on the other, a change of position by most participants within that network, which makes the result very different, despite being based on the same structure. Basically, this is because it is a very different thing to believe that farmers should save water rather than homes. The hypothetical impact this would have on water planning and public policy is enormous. Therefore, regardless of whether the preferences display instability over time in aggregate terms, from the point of view of the individuals' attitudinal network, they exhibit a much more coherent and knowledge-related behaviour pattern. Thus, for example, if half the participants who had learned in $\mathrm{t}^{2}$ preserve that learning six months later, we might expect this to generate a different picture within the individuals' usual attitudinal network, since they will have different preferences to those they had before deliberation within the same attitudinal schema.

Six months later, many participants were able to transfer what they had learned to their usual attitudinal networks, only now with more internal political efficacy, more knowledge and without the attitudinal inconsistency they displayed before deliberation. This result fits in with the postulates of normative theory, since it is not a question of deliberating indi- 
viduals changing completely, but of their becoming capable of opening up to the opinion of others and accepting decisions irrespective of whether or not they agree (Gutman and Thompson, 2004) according to their own comprehensive views of life. Preference structuration around the central issue of water saving, whether by homes or by farmers, is a good example of this. No one can uproot his own connections to life. Therefore, an intense deliberation process may have the virtue of making the individual reflect on his beliefs and attitudes, although this does not mean that in the long term he completely changes the view he had, but rather qualifies and changes his present attitudes. To an extent, the results of this study allow us to say that after intense deliberation the attitudinal network of individuals is more coherent than before. Thus we might imagine that their opinions will be more reasoned, which will also enable individuals to have a greater perception of political efficacy.

\section{Biblography}

Andersen, Vibeke N. and Kasper Hansen (2007): «How Deliberation Makes better Citizens: The Danish Deliberative Poll on the Euro", European Journal of Political Research, 46: 531-556.

Barabas, Jason (2004): «How Deliberation Affects Policy Opinion", The American Political Science Review, 98, 4: 687-701.

Besette, Joseph (1980): «Deliberative Democracy: The Majority Principle in Republican Government», en R. Goldwin and W. Schambra (eds.), How Democratic is the Constitution, Washington: American Entreprise Institute.

Brikman, Dannete and David Peterson (2006): «Public Opinion Reaction to Repeated Events", Political Behaviour, 28, 1: 87-112.

Chambers, Simone (2003): «Deliberative Democratic Theory", Annual Review of Political Science, 6: 307-326.

Chong, Dennis, Jack Citrin and Patricia Conley (2001): «When Self-interest Matters», Political Psychology, 22, 3: 541-570.
Cuesta, Maria, Joan Font, Ernesto Ganuza, Braulio Gómez and Sara Pasadas (2008): Encuesta Deliberativa, Cuadernos Metodológicos 42, Madrid: CIS.

Della Porta, Donatella (2005): «Deliberation in Movement: Why and How to Study Deliberative Democracy and Social Movements», Acta Politica, 40: 336-350.

Delli Carpini, Michael X., Fay L. Cook and Lawrence R. Jacobs (2004): «Public Deliberation, Discursive Participation and Citizen Engagement: A Review of the Empirical Literature», Annual Review Political Science, 7: 315-344.

Druckman, James and Kjersten Nelson (2003): «Framing and Deliberation: How Citizens' Conversations Limit Elite Influence», American Journal of Political Science, 47, 4: 729-745.

Dryzek, John and Christian List (2003): «Social Choice Theory and Deliberative Democracy: A Reconciliation», British Journal of Political Science, 33: 1-28.

Feldman, Stanley (1988): «Structure and Consistency in Public Opinion", American Journal of Political Science, 32, 2: 416-440.

Fishkin, James (1997): The Voice of the People: Public Opinion and Democracy, New Haven, CT: Yale University Press.

- (2003): «Consulting the Public through Deliberative Polling", Journal of Policy Analysis and Management, 22: 128-133.

Ganuza, Ernesto and Francisco Francés (2012): «The Deliberative Turn in Participation", European Political Science Review, 4, 2: 283-302.

Grönland, Kimmo, Maija Setälä and Kaisa Herne (2010): «Deliberation and Civic Virtue: Lessons from a Citizen Deliberation Experiment», European Political Science Review, 2, 1: 95-117.

Gutmann, Amy and Dennis Thompson (2004): Why Deliberative Democracy?, Princeton: Princeton University Press.

Hansen, Kasper M. (2004): Deliberative Democracy and Opinion Formation, Odense: University of Southern Denmark Press.

Huckfeldt, Robert, Jeannete M. Mendez and Tracy Osborn (2004): «Disagreement, Ambivalente and Engagement: The Political Consequences of Hereogeneous Networks», Political Psychology, 25, 1.

Jöreskog Karl G. and Dag Sörbom (1989): Lisrel 7: A Guide to the Program and Applications, Chicago: SPSS. 
Kline, Rex B. (1998): Principles and Practice of Structural Equation Modeling, New York: Guilford Press.

Kosnik, Lea-Rachel (2008): «Refusing to Budge: A Confirmatory Bias in Decision Making?», Mind Society, 7: 193-214.

Landwehr, Claudia (2005): «Rational Choice, Deliberative Democracy and Preference Transformation", Studies in Social and Political Thought, 11: 40-68.

- and Katharina Holzinger (2010): «Institutional Determinants of Deliberative Interaction", European Political Science Review, 2, 3: 373-400.

Mackie, Gerry (2006): «Does Democratic Deliberation Change Minds?», Politics, Philosophy and Economics, 5 (3): 279-303.

- (2008): «Deliberation, but Voting Too», Working Paper, University of California (online). http://dss. ucsd.edu/ gmackie/documents/DeliberationButVotingToo.pdf), Accessed 15 January 2011.

Mattei, Franco and Richard Niemi (2005): «Political Efficacy", in Sam Best and Bejamin Radcliffe (eds.), Pollin America: An Encyclopedia of Public Opinion, Westport, CT: Greenwood Press.

Mendelberg, Tali (2002): «The Deliberative Citizen: Theory and Evidence», in Delli Carpini, L. Hudy and R. Y. Shapiro (eds.), Research in Micropoliticis, volumen 6: Political Decision Making, Deliberation and Participation, New York: Elsevier Press.

Morrel, Michael (2005): «Deliberation, Democratic Decision-making and Internal Political Efficacy", Political Behavior, 27, 1: 49-69.

Moya, Carlos (1990): The Philosophy of Action, Cambridge: Polity Press.

Mutz, Diana (2006): Hearing the Other Side. Deliberative versus Participatory Democracy, Cambridge: Cambridge University Press.
Nelson, Thomas E., Zoe M. Oxley and Rosalee A. Clawson (1997): «Toward a Psychology of Framing Effects», Political Behavior, 19, 3: 221-246.

Petty, Richard E., Duane T. Wegener and Leandre R. Fabrigar (1997): "Attitudes and Attitude Change», Annual Review of Psychology, 48: 609-647.

—, Zakary L. Tormala, Pablo Briñol and Jarvis W. Blair (2003): «Implicit Ambivalence from Attitude Change: An Exploration of the PAST Model', Journal of Personality and Social Psychology, 90 (1): 21-41.

Searle, John R. (2004): Mind: A Brief Introduction, Oxford: Oxford University Press.

Steiner, Jurg, Andre Bächtiger, Markus Spörndli and Marco R. Steenbergen (2005): Deliberative Politics in Action, Cambridge: CUP.

Talpin, Julien (2011): Schools of Democracy, Colchester: ECPR Press.

Thompson, Dennis (2008): «Deliberative Democratic Theory and Empirical Political Science», Annual Review of Political Sciences, 11: 497-520.

Tormala Zakary L. and Richard E. Petty (2002): «What Doesn't Kill me Makes me Stronger. The Effects of Resisting Persuasion about Persons: Some Determinats and Implications", Journal of Personality and Social Psychology, 37: 1660-1672.

Wojcieszak, Magdalena, Young M. Back and Michael X. delli Carpini (2010): «Deliberative and Participatory Democracy? Ideological Strength and the Processes Leading from Deliberation to Political Engagement", International Journal of Public Opinion Research, 22, 2: 154-180.

Zaller, John (1992): The Nature and Origins of Mass Opinion, New York: Cambridge University Press.

- and Stanley Feldman (1992): «A Simple Theory of the Survey Respond: Answering Question versus Revealing Preferences", American Journal of Political Science, 36: 579-616. 
